Aerospace Science and Technology, Volume 88, May 2019, pp. 444-456

DOI: $10.1016 /$ j.ast.2019.03.040

\title{
Variable Rotor Speed and Active Blade Twist for Civil Rotorcraft: Optimum Scheduling, Mission Analysis, and Environmental Impact
}

\author{
Ioannis Goulos and Marco Bonesso ${ }^{\mathrm{a}}$ \\ ${ }^{a}$ Propulsion Engineering Centre, School of Aerospace Transport and Manufacturing \\ Cranfield University, Bedfordshire, MK43 OAL, UK
}

\begin{abstract}
The concepts of variable rotor speed and active blade twist constitute promising technologies in terms of improving the operational performance and environmental impact of rotorcraft. Modern civil helicopters typically operate using nearly constant main and tail rotor speeds throughout their operational envelope. However, previous research has shown that decreasing the main rotor speed within salient points of the operational envelope can result in a notable reduction of rotor power requirement, resulting in more efficient aircraft. This work aims to develop an integrated approach able to evaluate the potential improvements in fuel economy and environmental impact through optimum implementation and scheduling of variable rotor speed combined with active blade twist. A comprehensive rotorcraft analysis method is utilized, comprising models applicable to flight dynamics, rotor blade aeroelasticity, engine performance, gaseous emission prediction, and flight path analysis. A holistic optimization strategy comprising methods for Design of Experiment (DOE), Gaussian Process-based (GP) surrogate-modeling, and genetic optimization is developed. The combined framework is used to predict globally optimum variable rotor speed and active blade twist schedules resulting in minimum fuel consumption. The overall method is employed to assess the impact of the investigated concepts for a representative Twin-Engine Light (TEL) helicopter operating within realistic mission scenarios. The optimizations carried out suggest that variable rotor speed combined with active blade twist may result in mission fuel consumption and nitrogen oxides emission $\left(N O_{x}\right)$ reductions of the order
\end{abstract}

Preprint submitted to Aerospace Science and Technology

March 25, 2019 
of $5 \%$ and $8 \%$, relative to the fixed rotor speed case. The developed method constitutes an enabling technology for the investigation of novel technologies at multiple levels of assessment including aircraft-engine and mission levels.

Keywords: Helicopters, Aerodynamics, Gas turbines, Optimization, Surrogate modeling, Performance, Aero-elasticity, Environmental impact

\section{NOMENCLATURE}

\section{Roman Symbols}

$\Delta \dot{w}_{f}^{\text {Opt. }}(\%) \quad$ Engine fuel flow delta, $=100 \times \frac{\dot{w}_{f}^{\text {Opt. }}-\dot{w}_{f}^{\text {Nom. }}}{\dot{w}_{f}^{\text {Nom. }}},(\%)$

$\Delta F_{b}(\%) \quad$ Mission fuel burn delta, $=100 \times \frac{F_{b}^{\text {Opt. }}-F_{b}^{\text {Nom. }}}{F_{b}^{\text {Nom. }}},(\%)$

$\dot{w}_{f} \quad$ Engine fuel flow, $\mathrm{kg} / \mathrm{sec}$

$\mathrm{CO}_{2}^{\text {Rate }}, \mathrm{NO}_{x}^{\text {Rate }} \mathrm{CO}_{2}$ and $\mathrm{NO}_{x}$ production rates per engine, $\mathrm{kg} / \mathrm{sec}$

$F_{b} \quad$ Mission fuel consumption, $k g$

$h \quad$ Density altitude, $m$

$P_{\text {engine }} \quad$ Engine shaft power, Watt

PCN Normalized rotational speed, $\frac{(N)_{O D}}{(N)_{D P}}$, dimensionless

$R_{p}^{2} \quad$ Coefficient of determination for $p^{t h}$-order polynomial, dimensionless

$T_{m r}, T_{t r} \quad$ Main rotor and tail rotor thrust, Newtons

$V \quad$ True airspeed, $\mathrm{m} / \mathrm{sec}$

W Rotorcraft gross weight, $\mathrm{kg}$

\section{Greek Symbols}

$\epsilon, \sigma \quad$ Root-Mean-Square and standard deviation of RSM error, -

$\Omega \quad$ Main rotor speed, $\mathrm{rad} / \mathrm{sec}$

$\overline{\Omega^{\text {Opt. }}}(\%) \quad$ Rotor speed ratio, $=100 \times \frac{\Omega^{\text {Opt. }}}{\Omega^{\text {Nom. }}}$, dimensionless

$\theta_{t w} \quad$ Blade twist angle, deg

\section{Superscripts}

()$^{G G / F P T} \quad$ Referring to the gas-generator or free-power turbine, respectively

()$^{\text {Nom. }} \quad$ Referring to the nominal rotor configuration

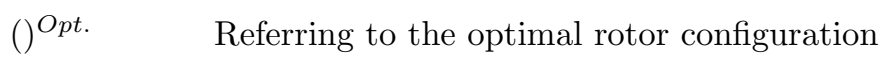




\section{Introduction}

\subsection{Background}

The concept of a variable rotor speed helicopter has been gaining increasing interest over the past two decades as a potential solution for the enhancement of overall aircraft performance [1, 2, 3]. Conventional helicopters usually employ a main rotor that runs at constant rotor speed $\Omega$ and is nominally powered by simple-cycle turboshaft engines [4. The incorporated powerplant configurations almost invariably employ a constant-speed Free-Power Turbine (FPT) and a fixed gearing-ratio transmission system. The rotational speed of the FPT is governed by the engine's Full Authority Control System (FADEC) by transiently adjusting the fuel flow to minimize any deviations in the FPT speed and rotor speed from the nominal value.

It is well-known that rotor power $\mathrm{P}$ for a given thrust $T$ increases proportionally to the cube of rotor speed $\Omega$. However, thrust is proportional to $\Omega^{2}$. Thus, for certain flight regimes, it is possible to produce a prescribed thrust $T$ with a reduced power requirement $P$ using a lower rotor speed $\Omega$ but higher blade loading to compensate for the associated thrust loss [5]. Furthermore, reducing the rotor speed at higher values of flight-speed reduces the adverse aerodynamic effects that manifest at the tip region of the advancing blades when the flow locally exceeds transonic velocities. These adverse flow features are not only responsible for a significant increase of power requirement at high-speed flight, but also for issues related to stability, control, and rotor-induced vibration [6].

\subsection{Variable rotor speed}

Steiner [1] explored the potential to reduce the main rotor power requirement by varying the rotor speed for the UH-60 Black Hawk helicopter. The obtained analytical results showed that the main rotor power requirement can be reduced by $17 \%$ within a true airspeed range of $25-60 \mathrm{~m} / \mathrm{sec}$. The reduction in power reached roughly $12 \%$ in hovering flight. Mistry and Gandhi [5] employed an analytical model to evaluate the potential to decrease the main rotor power 
requirement of the UH-60 helicopter by varying the rotor speed along with its radius over a range of air-speeds, gross weights, and altitudes. The results suggested that up to a $20 \%$ reduction in rotor power was feasible under "highand-heavy" conditions, for combined rotor speed reduction and radius increase.

Miste et al. [2] investigated numerically the performance implications of variable rotor speed for the UH-60A Black Hawk helicopter including the impact of rotor-engine integration. Miste et al. noted that incorporating the effect of engine coupling is essential for the determination of the optimum rotor speed for minimum fuel consumption. A fuel flow decrease of $7-8 \%$ was observed for rotor speed variations in the range of $\pm 15 \%$ relative to the nominal value.

Bowen-Davies and Chopra [6] explored the impact of rotor speed modulation on the performance and loads of the UH-60A helicopter rotor using the University of Maryland Advanced Rotorcraft Code (UMARC) [7. The authors of Ref. [6] noted that the feasible decrease in rotor power is a function of both air-speed as well as thrust level, with the largest abatement obtained at low thrusts. Furthermore, the in-plane rotor blade moments were found to increase at reduced rotor speed, whilst the vertical vibratory shear loads were unaffected.

More recently, Han et al. [8] employed an analytical model to assess the potential performance improvements for variable rotor speed helicopters by using fixed as well as retractable Gurney flaps. It was found that the deployment of fixed Gurney flaps can enhance the performance variable speed rotors and consequently expand the rotorcraft flight envelope. Furthermore, it was noted that $1 /$ rev retractable Gurney flaps can increase the obtained power reduction by almost $8.37 \%$ at high-speed flight conditions, compared to the fixed flap case.

For a given air-speed $V$ and rotor diameter $D$, a reduction in rotational speed $\Omega$ results in an increase in advance ratio. The impact of high advance ratios on the performance and aero-elastic loads of a slowed, four-bladed, Mach-scaled articulated rotor was numerically investigated by Bowen-Davies and Chopra [9]. The rotor flap bending moments were found to increase significantly with advance ratio. This was attributed to the proximity of the second flap mode to the 4/rev excitation frequency for the experimental apparatus used in their work. 


\subsection{Active blade twist}

In conjunction with variable rotor speed, another emerging technology in the design of rotary-wing aircraft is that of active rotor blade morphing. Active geometry control has been shown to be able to improve blade aerodynamics and overall rotor performance [10]. Different geometric morphing concepts have been proposed in the literature such as variable blade radius [5], variable blade chord [11, and active blade twist [12.

Active blade twist enables the rotor blades to change their washout angle through Individual Blade Control (IBC) or in a collective manner. The technology allows Higher Harmonic Control (HHC) inputs to be superimposed on the standard collective and cyclic pitch controls. The active modulation of blade twist can not only result in performance improvements, but also mitigate rotor-induced vibration [12]. Thus, it can be incorporated in conjunction with variable rotor speed to ameliorate adverse aero-mechanical phenomena 6, 9 .

Chen and Chopra 13 conducted an experimental investigation on a smallscale bearingless rotor model at hovering flight conditions using IBC. A linear twist variation of $0.6^{\circ}$ was achieved using embedded piezoelectric torsional actuators. This resulted in a reduction of vibratory thrust loads that reached up to $9 \%$ of the steady-state values. Wilbur et al. 14] performed an experimental campaign to assess the ability of active blade twist to reduce rotor vibratory loads. Their experimental apparatus comprised the four-bladed NASA/Army/MIT active twist rotor operated in the NASA Langley Transonic Dynamic Tunnel. Wilbur et al. noted that active twist control could offer reductions in fixed system loads of the order of $60 \%$ to $95 \%$, depending on flight conditions.

The impact of varying the blade twist angle on aerodynamic performance, induced vibration, and aero-acoustic impact was numerically investigated by Zhang et al. [15] using the DLR rotor simulation code S4 [16] and the DLR Reynolds-Averaged Navier-Stokes (RANS) flow solver FLOWer [17]. Zhang et al. concluded that a main rotor power reduction of the order of $14 \%$ was feasible, along with an $84 \%$ reduction of vibratory loads.

Han, Pastrikakis, and Barakos [18] investigated numerically the impact of 
combined variable rotor speed and blade twist through the adaptation both empirical as well as first-principles CFD analysis for an articulated rotor model based on the UH-60A utility helicopter. With reference to an airspeed of 250 $\mathrm{km} / \mathrm{h}$, the collective twist control alone provided up to $10.4 \%$ main rotor power reduction, while a reduction of $17.8 \%$ was achieved with rotor speed variations only. However, when combined, the two technologies raised this figure to $20.9 \%$.

\subsection{Scope of present work}

Several authors have examined the topics of variable rotor speed and active blade twist in the existing literature [1, 2, 3]. However, previous researchers have approached these concepts either strictly from an aero-mechanical standpoint [6, 9, 14, 19, or solely from an "isolated-rotor" point of view [5, 11, 13]. Although some recent references have tackled the problem from an "aircraftengine integration" perspective [2, 3], the effectiveness of these technologies at "mission level" where assessments are carried out under realistic operational procedures instead of idealized trim conditions, has not been investigated. Thus, the implications associated with the optimum scheduling of variable rotor speed and active blade twist during a complete mission when the aircraft trim-state and gross weight vary continuously with time, have not been examined in the literature. Moreover, the ramifications of these technologies on environmental impact in terms of gaseous $\mathrm{CO}_{2}$ and $\mathrm{NO}_{x}$ emissions have not been explored.

The objective of this work is to assess the potential improvements on the operational performance and environmental impact of rotorcraft, stemming from the implementation of optimal variable rotor speed and active blade twist schedules at mission level. A comprehensive rotorcraft code is deployed consisting of extensively validated models for flight dynamics [20, rotor blade aeroelasticity [21, engine performance [22], gaseous emission prediction [23, 24], and flight path analysis 25]. A computationally efficient Design Space Exploration (DSE) and optimization strategy is formulated comprising methods for DOE [26], Response Surface Modeling (RSM) [27, as well as genetic optimization [28].

The developed framework is deployed to acquire optimized rotor trim sched- 
ules in terms of variable rotor speed and active blade twist across the rotorcraft operational envelope using Gaussian Process (GP) surrogate modeling [27. The derived schedules are subsequently implemented within a mission analysis environment allowing optimal control of rotor speed and blade twist throughout any operational scenario. The overall approach is applied to evaluate the potential of the investigated technologies for a TEL rotorcraft modeled after the Airbus Helicopters Bo105, operating within realistic scenarios.

\section{Mathematical approach}

\subsection{Helicopter Omni-Disciplinary Research: HECTOR}

The numerical analyses reported in this paper have been carried out using the comprehensive rotorcraft code "HECTOR" (HEliCopTer Omni-Disciplinary Research) 25]. HECTOR incorporates modeling complexity suitable for rotor design applications in the context of operational performance and environmental impact assessments at mission level [23]. An advanced level of simulation fidelity is employed to capture the trade-off in performance between designs optimized in a multidisciplinary manner [29]. As a result, the design space can encompass the broader aircraft behavior within realistic mission scenarios, instead of idealized trim points with predefined flight conditions [24]. HECTOR has been continuously developed and refined at Cranfield University by Goulos et al. [25, 30. The code has been validated with experimental data in terms of airframe-rotor aerodynamics [31, 30, aeroelasticity [21, 20, engine performance [24, as well as gaseous emissions estimation [23, 24].

HECTOR comprises an automated work-flow of consecutive numerical analyses, each applicable to different aspects of rotorcraft aeroelasticity, flight dynamics, and performance. The incorporated models include the Lagrangian rotor blade modal analysis method developed in Refs. [32, 33, a flight path profile analysis based on the World Geodetic System dated in 1984 (WGS 84) [34, the non-linear trim procedure solving for the aeroelastic behaviour of the main rotor blades developed in Refs. [21, 31, 20, the engine performance analysis tool 
reported in Ref. [35], and the gas turbine emissions prediction model presented in Refs. [23, 24]. The individual processes are integrated in a holistic environment that solves for the unknown initial aircraft All-Up-Mass (AUM). A detailed description of HECTOR has been provided by Goulos et al. in Refs. 25, 23, 24.

\subsection{Aeroelastic rotor model}

The aeroelastic rotor model utilized for the purpose of this work incorporates the mathematical methods developed by Goulos et al. for the treatment of rotor blade elasticity in the time domain $21,31,20$. Figure 1 presents an upper-level block diagram that illustrates the architecture of the developed mathematical approach. The overall model includes the impact of non-linear inertial terms due to large blade deflections and aircraft maneuvering motions [20]. The employed rotor model includes the Peters-He finite state induced flow theory [36, 37] and the Leishman-Beddoes dynamic stall model for unsteady non-linear blade element aerodynamics [38]. Non-linear wake distortion effects due to maneuvering flight and rotor blade flapping are accounted for through the Goulos wake curvature model [39].

The natural vibration characteristics of the main rotor blades for flap, lag, and torsion are initially obtained using the minimum potential energy methods developed by Goulos et al. 32 and Castillo-Pardo et al 33 . The dynamic response of the elastic blades to any imposed aerodynamic or inertial excitation is calculated in the time domain using a fifth-order accurate numerical evaluation scheme of the convolution integral. The mathematical model of Cheeseman and Bennet theory [40] is employed for the treatment of ground effect on the aerodynamic environment of the main rotor for In-Ground Effect (IGE) operating conditions.

\subsection{Helicopter flight dynamics}

The employed flight dynamics model treats the aircraft fuselage as a rigid body with six degrees of freedom (three translations and three rotations). The 


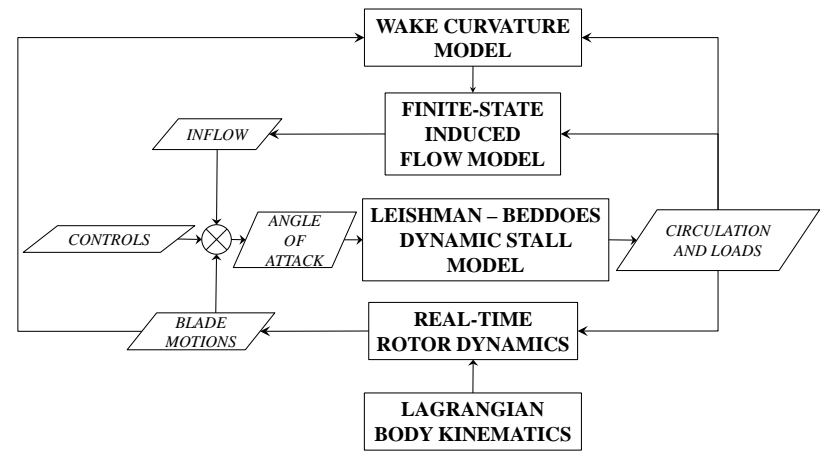

Figure 1: Aeroelastic rotor model block diagram

inertial tensors and fuselage mass information provided by Padfield [4 are utilized for the investigated rotorcraft. Look-up tables extracted from Ref. [4] are used for the prediction of fuselage aerodynamic coefficients. Discrete component maps [4] are incorporated for the estimation of the aerodynamic behavior of the horizontal and vertical stabilizers. Steady-state airfoil data along with first-order dynamic inflow [4] are used for the prediction of tail-rotor performance.

A globally-convergent Newton-Raphson method is employed to obtain the rotor trim control and fuselage attitude angles for any designated set of flight conditions. The main and tail rotors are marched synchronously in time using the initial condition of nonexistent circulatory wake. The time-marching process is completed when a once-per-rev periodic condition is achieved with respect to the main rotor multi-blade coordinates. After obtaining periodicity, a finite series of rotations is carried out where the main and tail rotor forces and moments are averaged in time, thus acquiring mean representative values to be used for trim.

\subsection{Gas turbine performance model (TURBOMATCH)}

The engine performance model (TURBOMATCH) used for the present work has been developed and refined at Cranfield University over a number of decades [35. Turbomatch is based on zero-dimensional aero-thermal analysis employing discrete component maps. The incorporated method essentially solves for the 
mass and energy balance between the various engine components. Turbomatch has been previously deployed in several studies available in the existing literature for the prediction of Design Point (DP), Off-Design (OD), and transient performance of gas turbine engines [22]. For the scope of this work, the engine is assumed to operate exclusively at steady-state OD conditions.

\subsection{Prediction of gaseous emissions (HEPHAESTUS)}

HEPHAESTUS is a generic software that was originally developed by Celis et al. for the estimation of gaseous emissions of civil aero-engines 42. HEPHAESTUS was further developed and validated by Goulos et al. 23] and OrtizCarretero et al. 24] for the prediction of gaseous emissions of helicopter turboshaft engines. A generic prediction methodology is incorporated based on the stirred reactor concept combined with a set of simplified chemical reactions. HEPHAESTUS accounts for the design specifications of the combustion system. Thus, the user can specify a combustor geometry in terms of primary, intermediate, and dilution zone volumes, as well as the associated air mass-flow fractions. HEPHAESTUS has been deployed in several optimization studies for regenerated helicopter turboshaft engines by Ali et al. [29].

\subsection{Flight path analysis model}

HECTOR employs a flight path model based on the WGS-84 34 for the analysis of realistic, three-dimensional rotorcraft operations. A user-defined mission scenario is divided into a sub-series of mission task elements (MTEs). Examples of MTEs include hover, climb, cruise, idle, etc. Each MTE features a set of user-defined parameters such as True Air-Speed (TAS), rate of climb/descent, altitude, etc. Once the mission has been set up, the geographical flight path definition (latitude, longitude, altitude) is translated to the Cartesian reference frame using a sixth order-polynomial representation of WGS-84 25]. Thus, the

employed flight path model enables the transition from an "aircraft-level" type of analysis to a complete "mission level" assessment. 


\subsection{Design space exploration and optimization}

In this work, HECTOR has been extended with the implementation of a computationally efficient optimization strategy. The goal is to rapidly obtain optimum schedules of variable rotor speed active and blade twist for designated mission scenarios, leading to minimum fuel consumption and gaseous emissions. A methodology has been devised that caters for the inherent non-linearity of the investigated design space, and reduces the computational overhead associated with multiple design iterations.

The structured analysis environment comprises modules for DSE, RSM (also referred to as surrogate modeling), parameter identification, and genetic optimization. The DSE method comprises two parts; (a) an initial DOE which strategically populates the design space, and (b) the formulation of RSMs using the DOE sample data. A DOE is a systematic approach to get the maximum amount of information out of a given sample. The Latin Hypercube Design (LHD) algorithm 43] has been selected for this work. Having completed the computational process driven by the LHD DOE, RSMs can be subsequently structured using the sample data as model inputs. Interpolation using Gaussian Processes Regression 27] (Kriging Interpolation) has been selected for the purpose of this work.

The proposed method utilizes the RSMs as drivers in the optimization process instead of relying directly on HECTOR simulations. The purpose is to mitigate the excessive computational overhead associated with numerous aeroelastic analyses, as required in an optimization environment. The structured RSMs are subsequently employed in combination with a genetic optimizer [28] "in-the-loop" during mission analysis. The goal is to instantaneously derive optimum combinations of variable rotor speed $\Omega$ and active blade twist $\theta_{t w}$ yielding minimum engine fuel flow $\dot{w}_{f}$ during each mission time-step. This process entails the deployment of a dedicated optimization per time-step, whereby the optimum combination of $\Omega$ and $\theta_{t w}$ is derived for prescribed values of aircraft weight $W$, TAS $V$, and altitude $h$. An illustration of the employed approach is shown in Fig. 2, A detailed description of the mission analysis method used in 


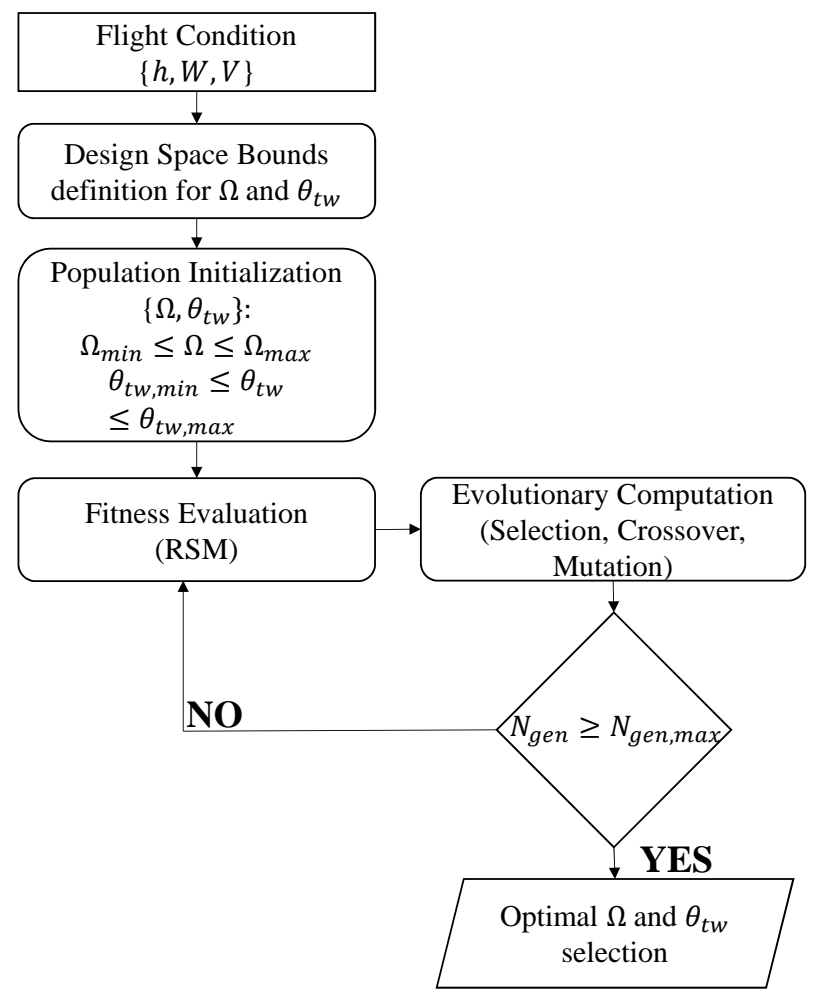

Figure 2: "In-the-loop" scheduling of optimal rotor speed $\Omega$ and active blade twist $\theta_{t w}$ targeting minimum engine SFC

HECTOR has been provided by Goulos et al. [25, 23.

The classical Leave-One-Out Cross-Validation (LOOCV) method [4] is deployed to evaluate the predictive accuracy of the structured RSMs prior to their utilization in an optimization environment. After successful derivation of sufficiently accurate RSMs for $\Omega$ and $\theta_{t w}$, the available design space can be systematically explored for potentially optimum control schedules. The selected optimization method has to be immune to the danger of being trapped within design space regions containing locally optimum solutions. Hence, the deployment of a global method is essential. The Non-dominated Sorting Genetic Algorithm II (NSGA-II) originally proposed by Deb et al. 28, has been selected for the purpose of this work. 
Table 1: Aircraft configuration for the baseline TEL utility helicopter

\begin{tabular}{lcc}
\hline Design parameter & Value & Unit \\
\hline \hline Bo 105 type rotorcraft & & \\
\hline Maximum Take-off Weight & 2500 & $\mathrm{~kg}$ \\
Number of blades & 4 & - \\
Blade radius & 4.91 & $\mathrm{~m}$ \\
Blade chord & 0.27 & $\mathrm{~m}$ \\
Blade twist & 8 & degrees \\
Nominal rotor speed & 44.4 & $\mathrm{rads} / \mathrm{sec}$ \\
\hline
\end{tabular}

\subsection{Helicopter and engine model configuration}

A generic TEL utility helicopter model has been employed for the purpose of this work. The baseline aircraft configuration has been modeled after the Airbus Helicopters Bo 105 rotorcraft. The most salient design parameters are outlined in Table 1. The selected aircraft is equipped with two Rolls-Royce Allison 250-C20B turboshaft engines rated at $313 \mathrm{~kW}$ maximum contingency shaft power. The maximum contingency power setting has been selected as the DP for the respective TURBOMATCH model. The model has been matched at DP conditions with publicly available information 45. The employed Bo 105 helicopter model has been extensively validated in terms of performance, loads, stability, and control by Goulos et al. 20, 31, 21, 30 using wind tunnel measurements and flight test data reported by Peterson [46] and Staley [47, respectively.

\subsection{Representative helicopter operational scenarios}

Three generic missions were defined representative of modern TEL rotorcraft operations; (a) a Passenger Air Taxi Mission (PATM), (b) a Law Enforcement Mission (LEM), and (c) a Search And Rescue Mission (SARM). The applied operational procedures in terms of TAS, altitude, climb/descent rates, and idle 

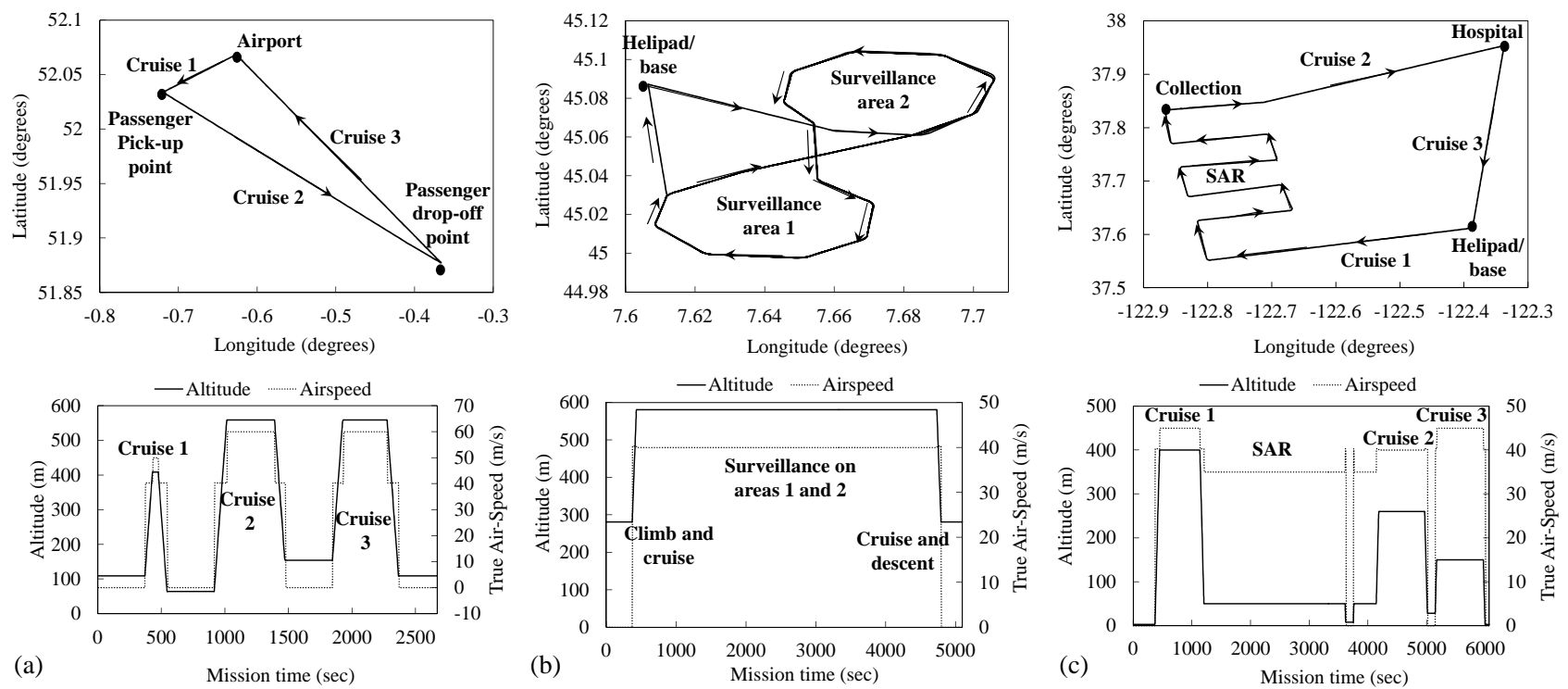

Figure 3: Defined rotorcraft operations - geographical representation in WGS84 and variation of true airspeed and altitude: (a) Passenger Air Transport Mission (PATM), (b) Law Enforcement Mission (LEM), (c) Search and Rescue Mission (SARM

times were defined in collaboration with the European Helicopter Operators' Committee (EHOC) [48].

Figures 3(a), (b), and (c) illustrate the geographical representations along with the employed operational procedures for the PATM, LEM, and SARM, respectively. With regards to the PATM operational schedule, the rotorcraft takes-off from Cranfield University airport (UK) and heads towards a designated passenger collection point in Milton Keynes (UK). Subsequently, the aircraft travels towards the London Luton International Airport where the passengers are dropped-off before the aircraft transits back to Cranfield Airport. With respect to the LEM schedule, the helicopter takes-off from Torino Aeritalia Airport (Italy) and subsequently transits towards a specified loitering urban region comprising two designated surveillance areas. Once the surveillance protocol is complete, the rotorcraft transits back to the original airport. The SARM schedule assumes that the helicopter takes-off from San Francisco International 
Airport (US) and travels towards an investigation zone. The helicopter is then assumed to engage in a search pattern to locate citizens in distress from a hypothetical naval incident location. After successful identification of the incident point, the helicopter SAR crew picks them up while hovering over the imaginary incident zone. The citizens are then transported to Brookside Hospital. The aircraft subsequently returns to San Francisco International Airport.

\section{Results and discussion}

A DSE activity was carried out to comprehend the impact of variable rotor speed and active blade twist on the performance and environmental impact of the investigated rotorcraft. This was accomplished with the adaptation of a fivedimensional design space that encompassed a combination of key flight envelope variables as well as rotor control and design parameters. The flight envelope design variables included the rotorcraft gross weight $W$, the density altitude $h$, and the aircraft TAS $V$. The rotor control and design parameters included the rotor speed $\Omega$ and the collective rotor blade twist $\theta_{t w}$ angle. The purpose behind the definition of a combined design space was to enable the subsequent generation of global RSMs that would allow the independent optimization of $\Omega$ and $\theta_{t w}$ for any designated point within the operational envelope in terms of $W$, $h$, and $V$. This enabled the derivation of optimized $\Omega$ and $\theta_{t w}$ schedules that were subsequently incorporated in a mission analysis environment.

The design space bounds were selected to envelop the wide range of flight and AUM conditions encountered in modern TEL rotorcraft operations [48]. A variation range between $75 \%$ to $115 \%$ was selected for $\Omega$ relative to the nominal value to capture both rotor under- and over-speed conditions, whilst $\theta_{t w}$ varied between $6^{\circ}$ and $16^{\circ}$. The selected bounds are shown in Table 2

\subsection{DOE approach}

The prescribed design space was discretized using 1,500 samples through the execution of the implemented LHD DOE approach [43]. Each sample represented a unique combination of $h, W, V, \Omega$, and $\theta_{t w}$ within the bounds show- 
Table 2: Definition of design space bounds for global DSE analysis

\begin{tabular}{lccc}
\hline Design variable & Min. value & Max. value & Unit \\
\hline Density altitude $(h)$ & 0 & 2000 & $\mathrm{~m}$ \\
Gross weight $(W)$ & 1400 & 2500 & $\mathrm{~kg}$ \\
True Air-Speed $(V)$ & 0 & 70 & $\mathrm{~m} / \mathrm{sec}$ \\
Rotor speed $(\Omega)$ & 35.52 & 48.84 & $\mathrm{rads} / \mathrm{sec}$ \\
Rotor blade twist $\left(\theta_{t w}\right)$ & 6 & 16 & degrees \\
\hline
\end{tabular}

cased in Table 2 A trim-point analysis was carried out using the Bo105 helicopter model in HECTOR 20] for each sample within the discretized design space. This process allowed to establish the associated trim values for main and tail rotor power requirement, as well as the shaft power $P_{\text {engine, }}$, fuel flow $\dot{w}_{f}$, and $S F C$ per engine. Furthermore, the associated environmental impact parameters were established in the form of gaseous emission production rates $(\mathrm{kg} / \mathrm{sec}), \mathrm{CO}_{2}^{\text {Rate }}$ and $\mathrm{NO}_{x}^{\text {Rate }}$, respectively.

A graphical illustration of the obtained DOE results is presented in Fig. 4 in terms of correlating shaft power per engine $P_{\text {engine }}$ with True-Air-Speed $V$. The results are analyzed using high-order polynomial regression [49] to understand the response of the design space. The colored marks denote HECTOR data, whilst the solid lines correspond to polynomial expressions fitted through the data. Regression analysis is carried out using up to $5^{\text {th }}$-order polynomial functions $(p=5)$. The calculated coefficients of determination $\left(R_{p}^{2} \in[0,1]\right)$ are also presented for each polynomial order $p$. The $R_{p}^{2}$ values indicate the average proximity of the HECTOR data to the fitted regression lines.

It can be observed that for $p \geq 2$ the correlation between $V$ and $P_{\text {engine }}$ follows the typical helicopter "bucket-shaped" power-curve trend [50]. The calculated values of $R_{p}^{2}$ reach their asymptotic range for $p \geq 2$ with $R_{p}^{2} \approx 0.712$. It can be noted that the HECTOR data are scattered around the higher-order regression lines that describe the impact of $V$ on $P_{\text {engine. }}$. The observed datascatter represents the impact of the remaining variables on $P_{\text {engine }}$, namely $h$, 


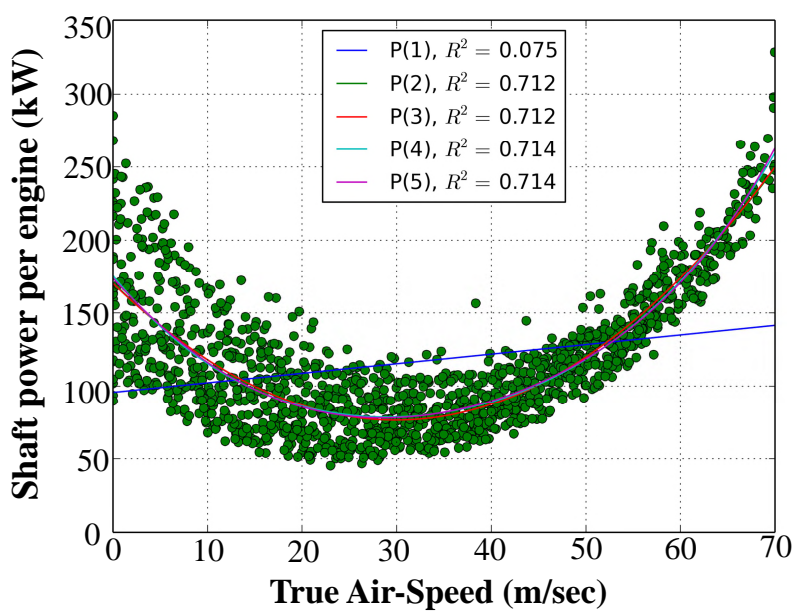

Figure 4: Design space behavior - Polynomial regression analysis of LHD DOE results: Correlation of $P_{\text {engine }}$ with True-Air-Speed $V$

$W, \Omega$, and $\theta_{t w}$. Furthermore, the range of data-scatter appears to reduce with $V$. This is due to the rapid rise of fuselage drag power with $V$ which dominates the rotocraft power requirement at high-speed flight. As a result, the impact of $V$ on $P_{\text {engine }}$ becomes progressively significant with increasing $V$ compared to the effect of the remaining variables $h, W, \Omega$, and $\theta_{t w}$.

\subsection{Surrogate modeling and cross-validation}

Having structured a data-base of HECTOR simulation data, the results were utilized to develop surrogate models (RSMs) that can approximate the response of the design space with sufficient accuracy. The employed method was based on Gaussian processes regression, also known as Kriging interpolation [27. The present Kriging model implementation employed a quadratic regression function combined with exponential auto-correlation.

The LOOCV approach [44] was utilized to assess the quality of the RSMs. The method is applied as follows: An RSM is created for each of the DOE data samples so that an RSM is uniquely associated with a specific sample-point. The data used to formulate each RSM include the entire range of DOE data with the exception of its corresponding sample-point. Subsequently, the sample- 


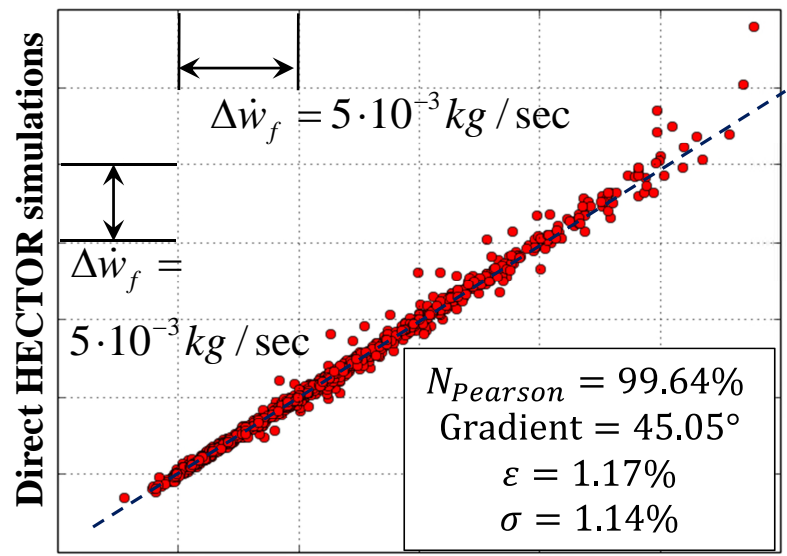

Surrogate model predictions

Figure 5: LOOCV applied to the RSM for engine fuel flow $\dot{w}_{f}$

point left-out of the data-base is compared against predictions made with its associated RSM. This process is repeated for all available DOE samples. The obtained RSM predictions are then cross-correlated against the original DOE results in terms of Pearson's product moment of correlation $N_{\text {Pearson }[51] \text { along }}$ with the gradient of the associated linear regression line.

This process is illustrated graphically in Fig. 5 for the RSM corresponding to the engine fuel flow $\dot{w}_{f}$. It is noted that a perfectly linear correlation corresponds to $N_{\text {Pearson }}=1(100 \%)$ and a regression line gradient of $45^{\circ}$. The computed values of $N_{\text {Pearson }}$ and line gradient when correlating RSM predictions with HECTOR data for $\dot{w}_{f}$ are of the order of $99.64 \%$ and $45.05^{\circ}$, respectively. The associated values for the mean RSM error $\epsilon$ and error standard deviation $\sigma$ are of the order of $1.17 \%$ and $1.14 \%$, respectively. Similar values of $\epsilon$ and $\sigma$ have been estimated for $\mathrm{CO}_{2}^{\text {Rate }}$ and $N O_{x}^{\text {Rate }}$. The computed quality metrics indicate the very good predictive accuracy of the structured RSMs.

\subsection{Optimized VRS and ABT scheduling}

Having developed accurate surrogate models that can predict the impact of $\operatorname{VRS}(\Omega)$ and $\operatorname{ABT}\left(\theta_{t w}\right)$ on the performance of the investigated rotorcraft, the models were deployed to derive optimum schedules of $\Omega$ and $\theta_{t w}$ as functions of 
gross weight $W$, density altitude $h$, and aircraft TAS $V$. This was accomplished with the deployment of the NSGA-II [28] algorithm applied to the minimization of $\dot{w}_{f}$ throughout the operational envelope using the constructed RSMs as drivers. Separate optimizations of $\dot{w}_{f}$ were carried out for prescribed variations of $W, h$, and $V$ using $\Omega$ and $\theta_{t w}$ as variables. The population size was set to 25 times the number of variables resulting in 50 chromosomes per generation. The incorporated mutation and crossover operators were defined according to the recommended practice suggested by Deb et al. 28, to ensure sufficient genetic diversity. A convergence criterion of $10^{-15}$ was applied on the average consecutive mutations per generation on the normalized design variables of $\Omega$ and $\theta_{t w}$. This criterion was attainable due to the fact that analytical RSMs were used during the optimization, instead of the non-linear numerical model (HECTOR).

Figures 69 present the optimum schedules for $\Omega$ and $\theta_{t w}$ as functions of $W, h$, and $V$. Each of the presented contour plots comprises approximately 56000 operating points within the rotorcraft flight envelope, for each of which a separate RSM-based optimization has been carried out. An effort was made to separate the impact of $\Omega$ and $\theta_{t w}$ on the performance benefits stemming from the investigated technologies. Thus, three separate types of optimization were carried out: (a) variable $\Omega$ and fixed $\theta_{t w}=\theta_{t w}^{N o m}$. (Fig. 6), (b) variable $\theta_{t w}$ and fixed $\Omega=\Omega^{\text {Nom. }}$ (Fig. 8 ), and (c) variable $\Omega$ and $\theta_{t w}$ (Fig. 9). Optimum rotor speed schedules are presented as percentage differences relative to the nominal values with $\overline{\Omega^{\text {Opt. }}}(\%)=100 \times \frac{\Omega^{\text {Opt. }}}{\Omega^{\text {Nom }} \text {. }}$. The optimization bounds were defined as shown in Table 2 for all cases. The associated operational benefits are presented as percentage differences in engine fuel flow $\dot{w}_{f}$ for the optimized schedules relative to the nominal configuration, $\Delta \dot{w}_{f}^{\text {Opt. }}(\%)=100 \times \frac{\dot{w}_{f}^{\text {Opt. }}-\dot{w}_{f}^{\text {Nom. }}}{\dot{w}_{f}^{\text {Nom. }}}$.

Figure 6 presents the computed optimum rotor control schedule for variable $\Omega$ and fixed $\theta_{t w}=\theta_{t w}^{N o m}$. as function of gross weight $W$, density altitude $h$, and aircraft TAS $V$. The variation of optimum rotor speed $\overline{\Omega^{O p t} \text {. }}(\%)$ relative to the nominal value is shown in Fig. 6(a). Numerical predictions are presented for three values of gross weight, $W=1600 \mathrm{~kg}, W=2000 \mathrm{~kg}$, and $W=2400 \mathrm{~kg}$. 

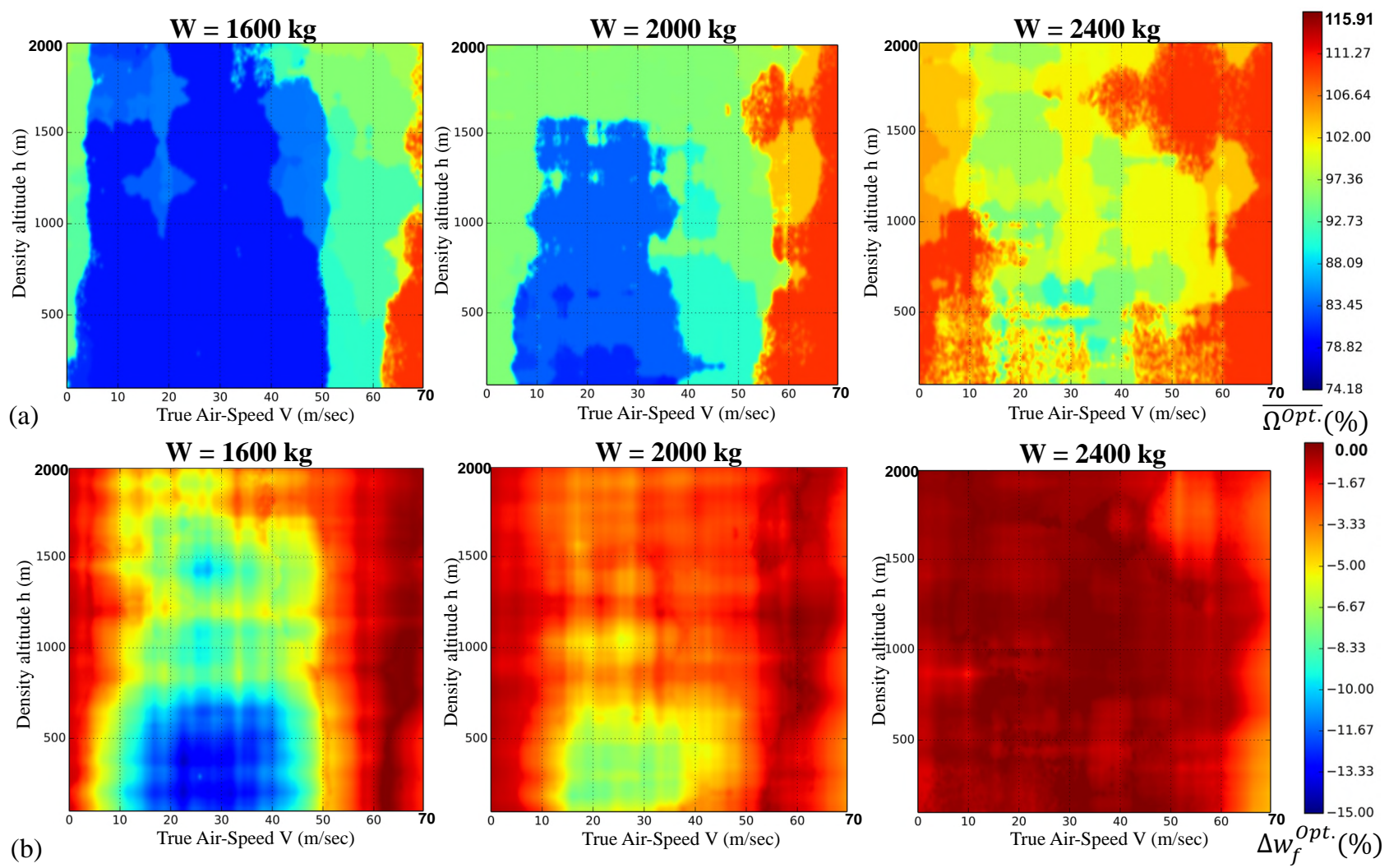

Figure 6: Optimized rotor control schedule for variable $\Omega$ and fixed $\theta_{t w}=\theta_{t w}^{N o m}$ as function of gross weight $W$, density altitude $h$, and aircraft TAS $V$ : (a) optimum rotor speed variation $\overline{\Omega^{O p t .}}(\%)$ and (b) engine fuel flow relative to nominal rotor configuration $\Delta \dot{w}_{f}^{O p t .}(\%)$

The impact of gross weight on optimum rotor speed $\overline{\Omega^{O p t}}$. $\%$ in noteworthy. Significantly reduced values of $\Omega$ can be noted for a low gross weight $W=$ $1600 \mathrm{~kg}$ with $\overline{\Omega^{\text {opt. }}}(\%) \approx 75 \%$ throughout the majority of the aircraft flight envelope. However, the flight envelope spectrum where diminished values of $\Omega$ are favorable appears to shrink with increasing $W$, with rotor over-speed regions occupying the majority of the flight envelope for $W=2400 \mathrm{~kg}$. For $W=1600 \mathrm{~kg}$, reduced values of $\Omega$ appear to be optimum for $V$ ranging between $40 \mathrm{~m} / \mathrm{sec}$ and $50 \mathrm{~m} / \mathrm{sec}$, with $75 \% \leq \overline{\Omega^{\text {Opt. }} .}(\%) \leq 85 \%$ depending on $h$. The flight speed range whereby a rotor speed reduction is favorable reduces with 
$h$. A rotor over-speed region with $\overline{\Omega^{\text {Opt. }}}(\%) \geq 110 \%$ can also be noted for low density altitudes $h \leq 1000 \mathrm{~m}$ and increased flight speed $V \geq 63 \mathrm{~m} / \mathrm{sec}$.

The behavior of optimum rotor speed illustrated in Fig. 6(a) is governed by aspects related to two fundamental disciplines: (a) rotor aerodynamics and (b) gas turbine performance. With respect to the former element, the effect of rotor speed on the aerodynamic behavior of the main rotor is through impacting on the profile power of the blades $[\mathbf{5}$. This is due to the resultant changes in the rotor dynamic head, as well as because of the modified blade loading associated with collective and cyclic pitch control variations required to satisfy thrust requirements. Reducing the rotor speed lowers the dynamic head encountered by the blades and reduces the overall blade profile drag power. However, a simultaneous raise in collective pitch is required to restore rotor thrust and sustain trimmed flight. This results in increased blade loading. Excessive values of blade loading have an adverse effect on airfoil aerodynamic efficiency which deteriorates the performance of the rotor. Thus, the value of rotor speed resulting in minimum profile power for a given thrust is that which corresponds to the optimum trade-off between the beneficial impact of reduced dynamic head and the adverse influence of increased blade loading.

With regards to the aspect of engine performance, Walsh and Fletcher 52 ] elaborated on the OD characteristics of turboshaft engines comprising a Gas Generator (GG) coupled to a Free-Power Turbine (FPT). For a given GG speedline $\left(P C N^{G G}=\frac{\left(N_{1}\right)_{O D}}{\left(N_{1}\right)_{D P}}\right)$ there is a unique FPT speed $\left(P C N^{F P T}=\frac{\left(N_{F P T}\right)_{O D}}{\left(N_{F P T}\right)_{D P}}\right)$ that simultaneously maximizes shaft power output and minimizes SFC. This effect is illustrated in Fig. 7 where the impact of normalized FPT speed $\left(P C N^{F P T}\right)$ on normalized SFC $\left(\frac{S F C}{S F C_{P C N^{F P T}=100 \%}}\right)$ is presented for a range GG speedlines $\left(P C N^{G G}\right)$. Engine performance simulations were carried out for the Allison 250-C20B engine at Sea-Level Static (SLS) conditions using the TURBOMATCH model employed in this work [23]. It can be observed that the optimum value of FPT speed is uniquely dependent on the GG shaft speed.

Furthermore, it can be noted that for a GG shaft speed of $100 \%$ corresponding to maximum contingency power setting, the optimum FPT speed that yields 


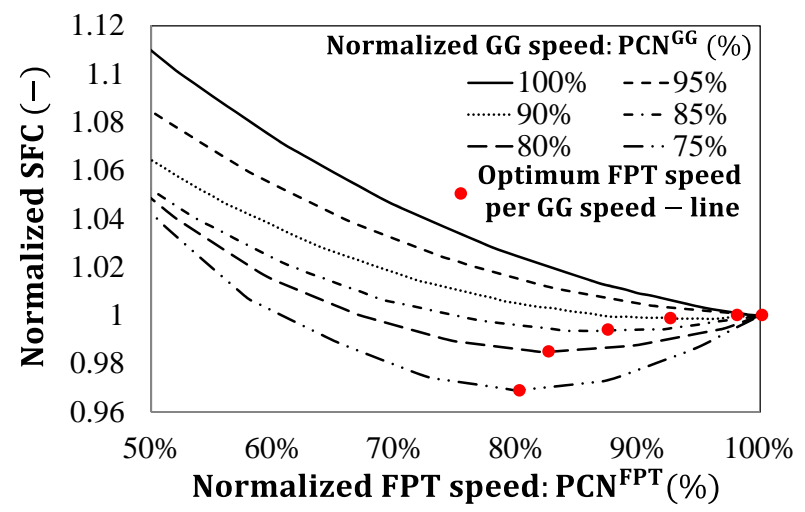

Figure 7: Impact of normalized FPT and GG shaft speed on engine Specific Fuel Consumption (SFC): Simulations carried out at Sea-Level Static (SLS) conditions

minimum SFC is also $100 \%$. For constant rotor speed helicopters with a fixed gearing-ratio, the nominal value of rotor speed $\Omega$ corresponds to $100 \%$ of FPT speed. However, Fig. 7 shows that for reduced GG speeds below the maximum power setting, the thermodynamically optimum FPT speed reduces with GG speed. As a result, for part-power settings an appropriately reduced value of rotor speed, and consequently FPT speed for a fixed gearing ratio, allows the GG shaft to settle at reduced rotational speeds resulting in reduced SFC and therefore fuel flow. However, an excessive reduction of FPT speed below the optimum value, requires the GG to settle at higher-shaft speeds compared to the $100 \%$ FPT case, leading to increased SFC and fuel consumption.

Thus, similar to the case of rotor aerodynamics, there is an optimum FPT speed that is uniquely dependent on the GG power settings. The aerodynamically and thermodynamically optimum values of rotor speed may be different. As a result, for a fixed gearing ratio, fuel flow optimization entails finding the best compromise between the aerodynamically optimum rotor speed and the thermodynamically optimum FPT speed. Hence, it is understood that the process of obtaining optimum rotor speed schedules that maximize the coupled rotor-engine performance is a multi-disciplinary process that requires to account for the trade-off between rotor aerodynamics and engine thermodynamics. 
It was previously noted that the rotorcraft gross weight $W$ has a significant impact on the optimum rotor speed schedule. Figure 6(a) shows that an increase in $W$ leads to a consistent increase in $\overline{\Omega^{O p t}}$. $\%$ throughout the investigated flight envelope. This is due to the associated increment in rotor thrust which limits the potential to reduce $\Omega$ due to the excessive increase in blade loading for a given thrust setting which penalizes rotor aerodynamic performance.

Figure 6(b) presents the predicted improvements in fuel consumption due to optimum rotor speed scheduling. Results are presented as percentage differences relative to the nominal rotor speed case $\Delta \dot{w}_{f}^{O p t}(\%)$. The impact of variable $\Omega$ is more prominent within parts of the operational envelope where profile power dominates over the induced and parasitic counter-parts. The maximum observed change in $\Delta \dot{w}_{f}^{\text {Opt. }}(\%)$ is of the order of $-12 \%$ and is obtained for low values of gross weight $(W=1600 \mathrm{~kg})$, low density altitudes $(h \leq 750 \mathrm{~m})$, and is centered around the speed for maximum endurance $(20 \mathrm{~m} / \mathrm{sec} \leq V \leq 40 \mathrm{~m} / \mathrm{sec})$.

Furthermore, Fig. 6.(b) shows that the potential improvements in $\Delta \dot{w}_{f}^{\text {Opt. }}(\%)$ associated with variable $\Omega$ diminish with increasing gross weight $W$. Negligible improvements can be noted throughout the majority of the flight envelope for $W=2400 \mathrm{~kg}$ with $\Delta \dot{w}_{f}^{\text {Opt. }}(\%) \geq-0.5 \%$ for $V \leq 60 \mathrm{~m} / \mathrm{sec}$ and independently of $h$. However, the improvements in $\Delta \dot{w}_{f}^{\text {Opt. }}(\%)$ reach roughly $-3 \%$ for $V \geq$ $60 \mathrm{~m} / \mathrm{sec}$ when the $\overline{\Omega^{O p t}}$. schedule forces the rotor into the over-speed region.

Figure 8 illustrates the optimum control schedule for variable rotor blade twist angle $\theta_{t w}$ and fixed $\Omega=\Omega^{N o m}$. The variation of optimum $\theta_{t w}$ is shown in Fig. 8(a), whilst the associated improvement in fuel consumption $\Delta \dot{w}_{f}(\%)$ is presented in Fig. 8 (b). Contrary to the case of variable $\Omega$, alterations in $\theta_{t w}$ affect predominantly the behavior of rotor induced power. As such, the impact of $\theta_{t w}$ on $\Delta \dot{w}_{f}(\%)$ appears to be pronounced within parts of the flight envelope where the induced power component dominates over the respective profile and parasitic counter-parts. Figure 8 (a) demonstrates that the optimum $\theta_{t w}$ schedule comprises regions reaching $16^{\circ}$ for near hover $(V \approx 0)$ and low flight-speed flight $(V \leq 20 \mathrm{~m} / \mathrm{sec})$. At these conditions, the impact of increasing $\theta_{t w}$ is to modify the radial variation of blade circulation and to establish a more 
uniform inflow distribution which results in a reduction of rotor induced losses.
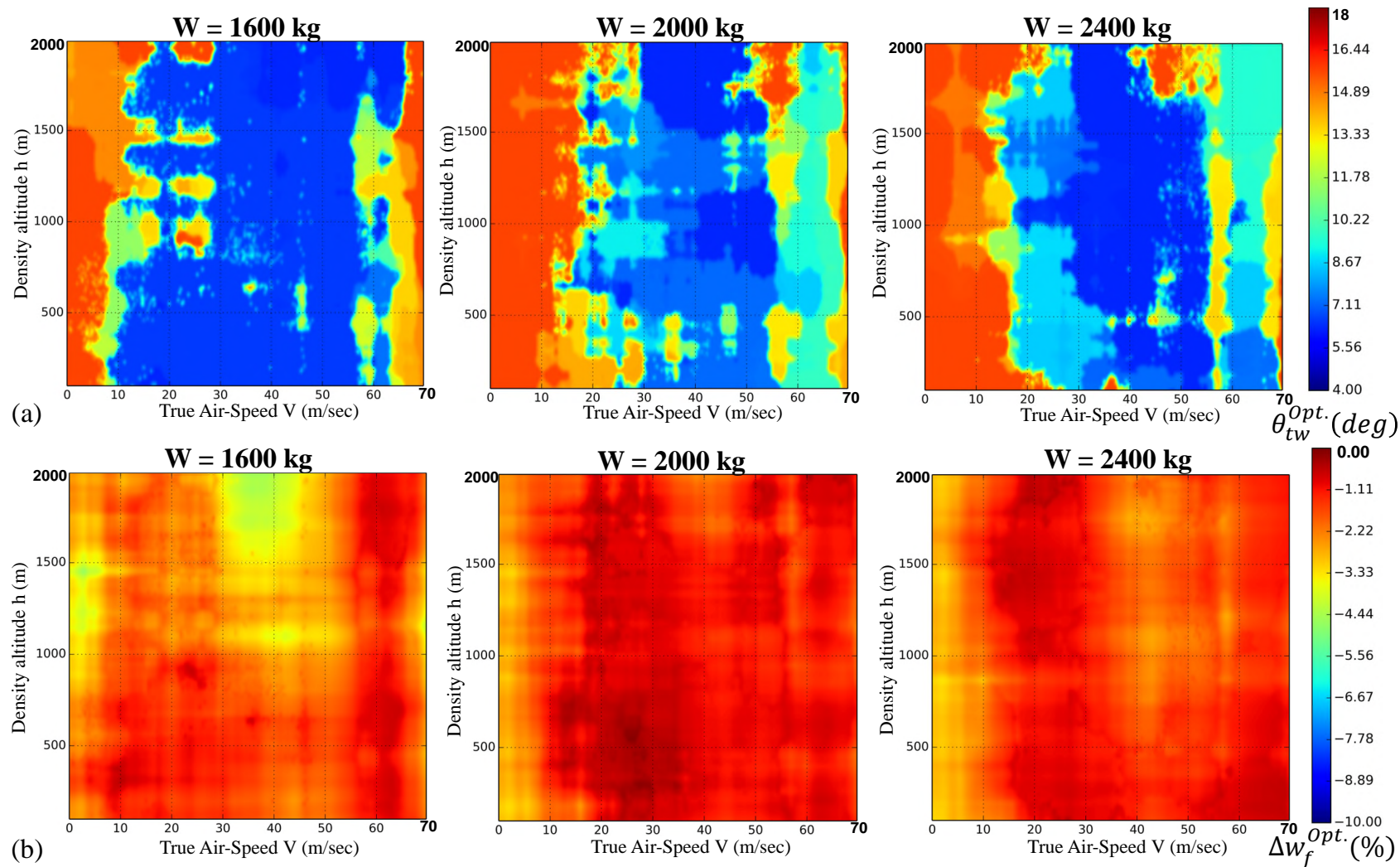

Figure 8: Optimized rotor control schedule for variable $\theta_{t w}$ and fixed $\Omega=\Omega^{N o m}$. as function of gross weight $W$, density altitude $h$, and aircraft TAS $V$ : (a) optimum rotor blade twist $\theta_{t w}^{O p t .}(d e g)$ and (b) engine fuel flow relative to nominal rotor configuration $\Delta \dot{w}_{f}^{O p t}$. (\%)

Figure 8 (b) shows that the influence of $\theta_{t w}$ is more pronounced for low-speed flight $(V \leq 20 \mathrm{~m} / \mathrm{sec})$ with $\Delta \dot{w}_{f}(\%)$ ranging between $-4 \%$ and $-2 \%$, depending on $h$ and $W$. Negligible improvements are noted with respect to the remainder of the flight envelope with $\Delta \dot{w}_{f}(\%) \leq-1.5 \%$ for $V \geq 20 \mathrm{~m} / \mathrm{sec}$, with the exception of the low aircraft weight case $(W=1600 \mathrm{~kg})$ where an improvement of $\Delta \dot{w}_{f}(\%) \approx-3.5 \%$ can be observed around the maximum endurance flight speed $(30 \mathrm{~m} / \mathrm{sec} \leq V \leq 45 \mathrm{~m} / \mathrm{sec})$ at relatively high-altitude $(h \geq 1500 \mathrm{~m})$. Overall, the improvements in fuel consumption relative to the baseline rotor appear to 
be consistently lower compared to the optimized $\Omega$ schedule shown in Fig. 6(b).

Figures 9 (a) and (b) present the optimized schedules when both variable $\Omega$ and $\theta_{t w}$ are considered simultaneously. It can be observed that the combined optimization has not resulted in fundamentally different distributions of $\Omega$ and $\theta_{t w}$ relative to the individual cases. This is due to the fact that the optimizations carried out for $\Omega$ and $\theta_{t w}$ target independent, to first-order, components of rotor power requirement. However, the combined optimization has allowed the implementation of a holistic control strategy that tackles a multitude of rotor aerodynamic and gas turbine performance aspects. The optimized control of $\Omega$ allows to obtain the best trade-off between blade profile losses and FPT efficiency, whilst the optimization of $\theta_{t w}$ allows to minimize rotor induced losses.

Figure 9(c) illustrates the percentage differences in fuel flow $\Delta \dot{w}_{f}(\%)$ relative to the nominal rotor configuration. The benefits of the combined optimization relative to the individual cases can be observed. The maximum change in $\Delta \dot{w}_{f}^{\text {Opt. }}(\%)$ reaches approximately $-15 \%$. Similar to the behavior noted for the isolated variable $\Omega$ case (Fig. 6), the maximum attainable reduction in $\dot{w}_{f}$ is observed for the lowest gross weight $(W=1600 \mathrm{~kg}$ ) near the vicinity of maximum endurance flight speed $(25 \mathrm{~m} / \mathrm{sec} \leq V \leq 35 \mathrm{~m} / \mathrm{sec})$. However, the combined optimization of $\Omega$ and $\theta_{t w}$ has expanded the operational envelope to higher density altitudes $(h \geq 750 \mathrm{~m})$ within which notable improvements in $\dot{w}_{f}$ are attained.

The most salient reductions in engine fuel consumption are obtained for low values of gross weight $(W=1600 \mathrm{~kg})$ where $\Delta \dot{w}_{f}^{\text {Opt. }}(\%)$ varies between $-15 \%$ and $-3 \%$ throughout the majority of the flight envelope depending on $h$ and $V$. The affected region is confined near the vicinity of the maximum endurance flight speed $(25 \mathrm{~m} / \mathrm{sec} \leq V \leq 45 \mathrm{~m} / \mathrm{sec})$ within low and median values of density altitude $h \leq 1500 \mathrm{~m}$. However, the flight envelope part where a substantial reduction in $\dot{w}_{f}$ is attainable is expanded relative to the isolated variable $\Omega$ case shown in Fig. 6(b). For larger values of gross weight $(W=2400 \mathrm{~kg})$ the obtained reduction in $\dot{w}_{f}$ is limited at near-hover conditions $(V \leq 5 \mathrm{~m} / \mathrm{sec})$ with $\Delta \dot{w}_{f}^{O p t .}(\%) \approx-6 \%$, as well as for high-speed flight $(V \geq 65 \mathrm{~m} / \mathrm{sec})$ and highaltitude regimes $(h \geq 1600 \mathrm{~m})$. This is due to the strong combination of induced 

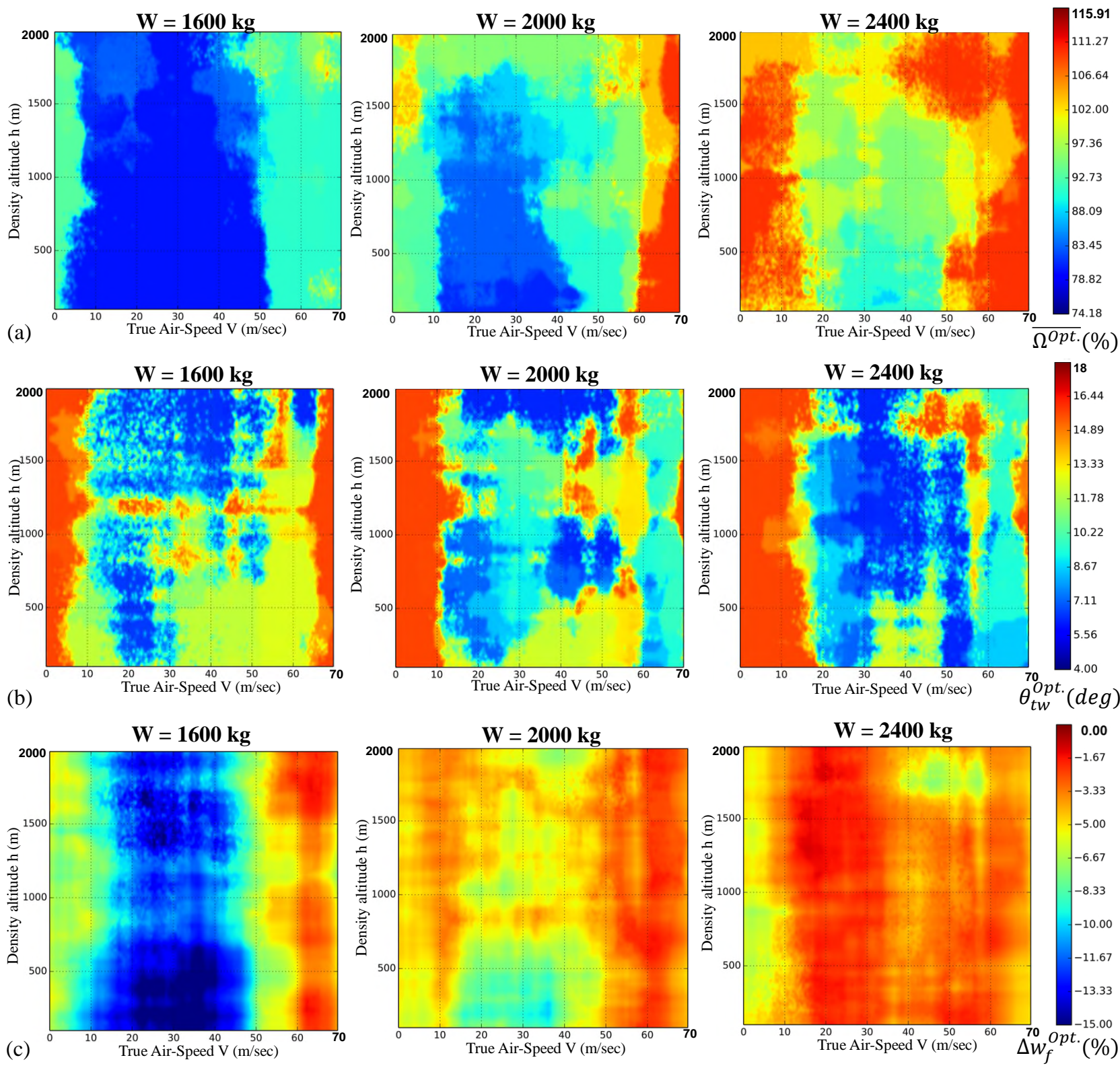

Figure 9: Optimized rotor control schedule for variable $\Omega$ and $\theta_{t w}$ as function of gross weight $W$, density altitude $h$, and TAS $V$ : (a) optimum rotor speed variation $\overline{\Omega^{O p t} \text {. }}(\%$ ), (b) optimum blade twist $\theta_{t w}^{O p t .}(\mathrm{deg})$ and (c) engine fuel flow relative to nominal configuration $\Delta \dot{w}_{f}^{O p t .}(\%)$ 
and blade profile losses that dominate within this part of the flight envelope.

The results presented and discussed within this section allowed to produce novel optimum schedules of $\Omega$ and $\theta_{t w}$ across the operational envelope of a TEL rotorcraft modeled after the Airbus Helicopters Bo105. The impact of novel optimum $\Omega$ and $\theta_{t w}$ scheduling on $\dot{w}_{f}$ was quantified for the combined helicopter-engine system across the investigated range of flight conditions, whilst the governing aerodynamic and thermodynamic flow-mechanisms were exposed. Furthermore, the individual impact of $\Omega$ and $\theta_{t w}$ on "aircraft-level" performance was delineated through the derivation of separate rotor control schedules in terms of: $\Omega$ (Fig. 6), $\theta_{t w}$ (Fig. 8), as well as combined $\Omega$ and $\theta_{t w}$ (Fig. 9).

\subsection{Mission analysis and environmental impact}

The operational benefits and environment impact stemming from the implementation of optimum $\Omega$ and $\theta_{t w}$ schedules were assessed within a holistic mission analysis environment. Numerical predictions were carried out for three control strategies: (a) variable $\Omega$ and fixed $\theta_{t w}=\theta_{t w}^{N o m}$, (b) variable $\theta_{t w}$ and fixed $\Omega=\Omega^{N o m}$, and (c) variable $\Omega$ and $\theta_{t w}$. The derived schedules were employed using the method described in section 2.7. Comparative evaluations were carried out relative to the nominal rotor with fixed $\Omega=\Omega^{N o m}$ and $\theta_{t w}=\theta_{t w}^{N o m}$.

The developed rotor control strategy is based on the deployment of RSMs that are applicable to straight and level flight. As a result, the incorporated method for the optimum scheduling of $\Omega$ and $\theta_{t w}$ does not account for the aerodynamic impact of Flight Path Angle (FPA) employed during climbing and descending flight. Thus, to evaluate the potential of the investigated technologies across complete operations, a parametric analysis was carried out using HECTOR to determine the impact of FPA on the optimum $\Omega$. It is noted that fixed values of $V$ as well as climb and descent rates were employed for the assessments reported in this article with $F P A \approx \pm 7.12^{\circ}$ and $V=40 \mathrm{~m} / \mathrm{sec}$. Thus, the optimum scheduling of $\Omega$ during climb and descent was implemented as a unique function of gross weight $W$ only on the basis of minimizing $\dot{w}_{f}$. Table 3 summarizes the employed scheduling of $\Omega$ for climbing and descending flight. 

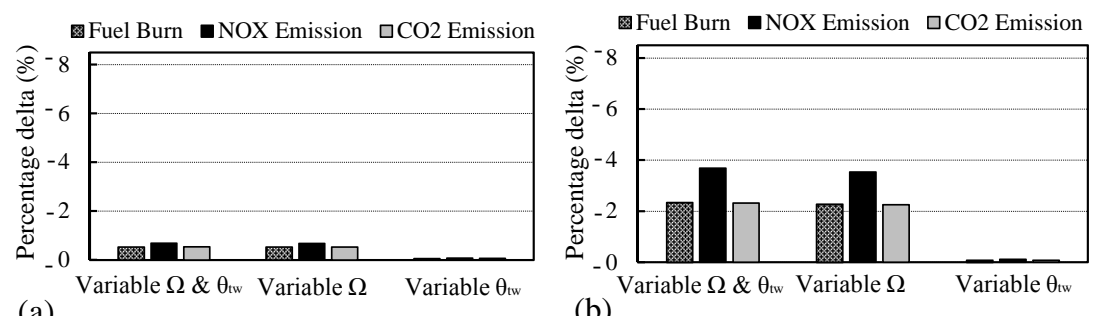

(b)

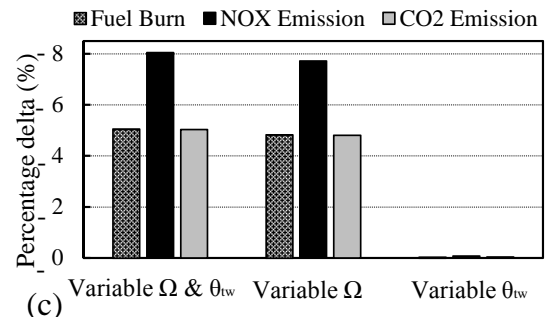

Figure 10: Impact of optimum $\Omega$ and $\theta_{t w}$ scheduling on mission fuel burn, $\mathrm{NO}_{x}$, and $\mathrm{CO}_{2}$ gaseous emissions: (a) PATM, (b) LEM, (c) SARM

$\theta_{t w}$ was held fixed to the nominal value $\theta_{t w}=\theta_{t w}^{N o m}$. due to its smaller impact.

Table 3: Prescribed $\Omega$ and $\theta_{t w}$ settings for climbing and descending flight conditions

\begin{tabular}{lccc}
\hline Flight condition & $W(\mathrm{~kg})$ & $\bar{\Omega}(\%)=\frac{\Omega}{\Omega^{\text {Nom. }}}$ & $\theta_{t w}^{\circ}$ \\
\hline Climb & Any & $100 \%$ & 8 \\
Descent & $2300 \leq W \leq 2500$ & $95 \%$ & 8 \\
Descent & $2100 \leq W \leq 2300$ & $90 \%$ & 8 \\
Descent & $W \leq 2100$ & $85 \%$ & 8 \\
\hline
\end{tabular}

Figure 10 illustrates the impact of the optimum $\Omega$ and $\theta_{t w}$ schedules on mission fuel burn and environmental impact in terms of $\mathrm{NO}_{x}$ and $\mathrm{CO}_{2}$ emissions. Numerical predictions are shown for the PATM, LEM, and SARM operations in Figs. 10(a), (b), and (c), respectively. The results are presented as percentage differences relative to mission analyses carried out with fixed $\Omega=\Omega^{N o m}$. and $\theta_{t w}=\theta_{t w}^{N o m}$. values, e.g. for fuel burn it applies that $\Delta F_{b}(\%)=$ $100 \times \frac{F_{b}^{\text {Opt. }}-F_{b}^{\text {Nom. }}}{F_{b}^{\text {Nom. }}}$, with similar expressions employed for $\mathrm{NO}_{x}$ and $\mathrm{CO}_{2}$.

It can be observed that the predicted improvements in performance and environmental impact are dependent on the type of operation. The implementation of a combined optimization strategy for both $\Omega$ and $\theta_{t w}$ has lead to a delta in fuel burn and $\mathrm{CO}_{2}$ emissions of the order of $-0.5 \%,-2.1 \%$, and $-5.0 \%$ for the PATM, LEM, and SARM operations, respectively. The associated deltas in the production of $N O_{x}$ gaseous emissions reach approximately $-0.67 \%,-3.88 \%$, and 

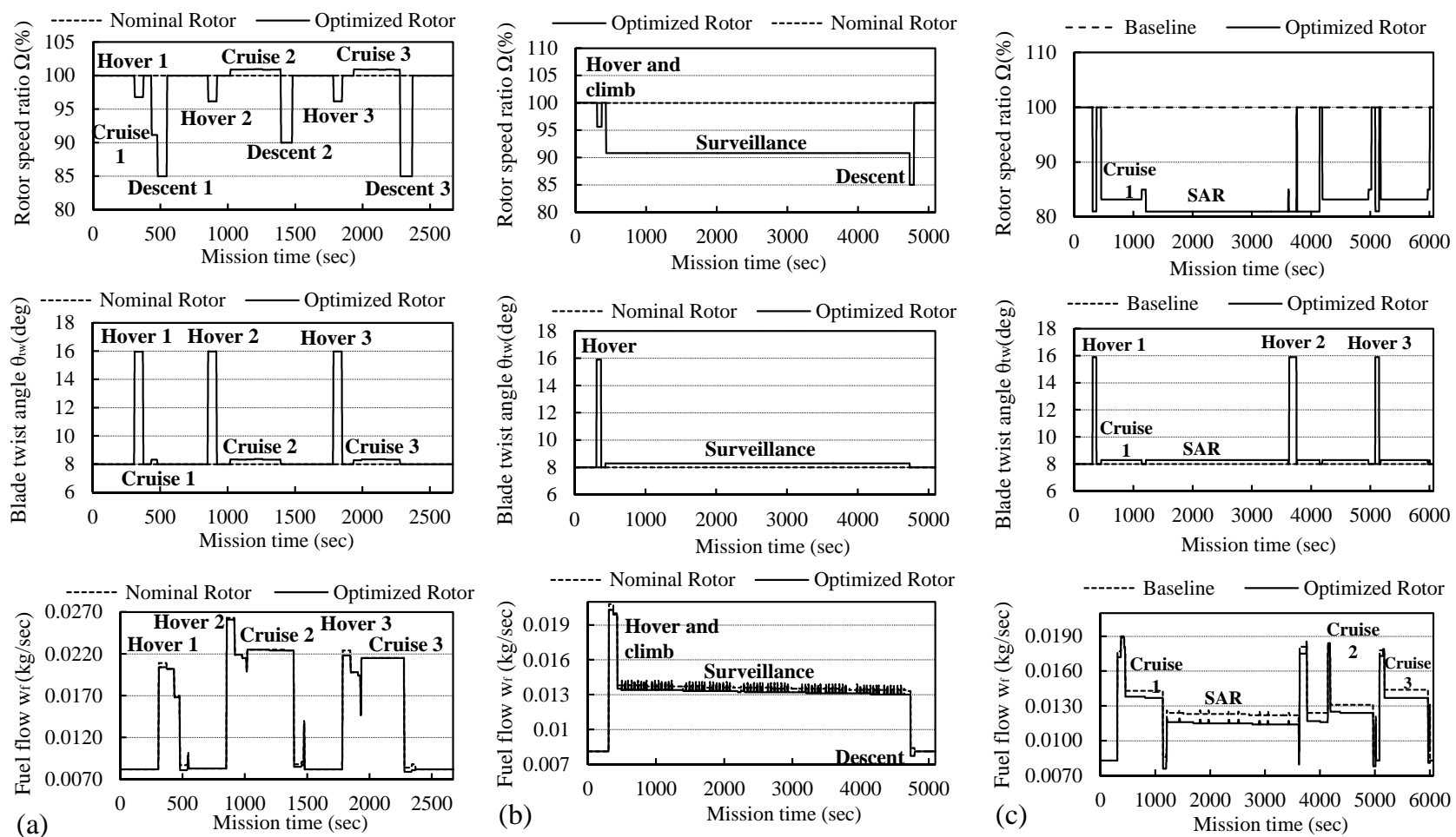

Figure 11: Optimum scheduling of $\Omega, \theta_{t w}$, and $\dot{w}_{f}$ performance comparison for the defined mission scenarios with nominal rotor configuration: (a) Passenger Air Transport Mission (PATM), (b) Law Enforcement Mission (LEM), (c) Search and Rescue Mission (SARM)

$-7.91 \%$, in that order. The variability observed in the performance deltas within the investigated operations is close to an order of magnitude. The achieved fuel burn reduction per mission is highly dependent on the proximity of the operating conditions to the "high-potential" zone of the operational envelope where the impact of variable $\Omega$ and $\theta_{t w}$ is considerable, as illustrated in Fig. 9(c).

Figure 10 also shows that the obtained improvements in fuel burn and gaseous emissions stem primarily due to the impact of $\Omega$, whilst the influence of $\theta_{t w}$ appears to be marginal. This behavior applies with regards to all investigated rotorcraft operations and is consistent with the optimization results presented and discussed in section 3.3. It has been demonstrated in Figs. 69 that the impact of optimal $\theta_{t w}$ scheduling on $\dot{w}_{f}$ is small compared to the influ- 
ence of $\Omega$. Furthermore, the effect of $\theta_{t w}$ is limited predominantly at near-hover flight conditions. Although all of the investigated operations (Fig. 3 include frequent occurrences of hovering flight, their duration is limited.

With respect to the PATM operation Fig. 3(a) shows that, with the exception of the "idle" segments, the rotorcraft spends the majority of the mission time within high-speed cruise, descent, or climbing flight. These conditions are removed from the "high-potential" zone of the operational envelope where the impact of variable $\Omega$ and $\theta_{t w}$ is formidable (Fig. 9 (c)). As a result, the improvements in performance and environmental impact were found to be marginal.

This behavior is further illustrated in Fig. 11(a) which depicts the optimum schedule of $\Omega$ and $\theta_{t w}$ for the PATM operation, along with the distribution of $\dot{w}_{f}$. It can be noted that with respect to the "hover" segments, the control schedule has applied a reduction in $\overline{\Omega^{O p t}} \approx 96.5 \%$ combined with a large increase in $\theta_{t w}^{O p t .} \approx 16^{\circ}$. This is attributed to the favorable impact of blade twist on rotor induced power. However, the variation of $\theta_{t w}^{O p t}$. appears to be marginal throughout the remainder of the mission. A larger decrease in $\Omega$ is observed during the first cruise segment with $\overline{\Omega^{O p t}} \approx 91 \%$. This is followed by a larger reduction within the first occurrence of descending flight with $\overline{\Omega^{\text {opt }}} \approx 85 \%$. The optimum value of $\overline{\Omega^{O p t}}$. is increased to $90 \%$ for the second descent segment due to the larger aircraft weight, after collecting passengers at the "pick-up" point. A slight rotor over-speed has been applied within the second and third cruise parts with $\overline{\Omega^{O p t} .} \approx 101 \%$ due to the increased $V$. However, the obtained reductions in $\dot{w}_{f}$ are marginal and limited primarily within hovering flight.

Figures 11(b) and (c) present the derived optimal schedules of $\Omega$ and $\theta_{t w}$, along with the time-dependent distributions of $\dot{w}_{f}$ for the LEM and SARM operations, respectively. It can be observed that the employed rotor speed schedule has induced substantial variations of $\overline{\Omega^{O p t}}$ throughout the majority of the mission duration with regards to both operations. This is due to the fact that, contrary to the PATM operation, the rotorcraft is engaged in lowaltitude loitering activities at near maximum-endurance airspeed regarding both operations. Thus, the rotorcraft operates within the "high-potential" zone of 
the flight envelope where the impact of variable $\Omega$ and $\theta_{t w}$ is notable. However, the variation of $\theta_{t w}^{O p t}$. appears to be marginal throughout both missions with the exception of "hover" segments where the maximum $\theta_{t w}$ value has been applied.

Figure 3(b) illustrates that with regards to the LEM operation, the rotorcraft engages for approximately $90 \%$ of the mission duration in a surveillance operation with $h \approx 600 \mathrm{~m}$ and $V=40 \mathrm{~m} / \mathrm{sec}$. Figure 11 (b) shows that the rotor control schedule has opted for $\overline{\Omega^{O p t} .} \approx 91 \%$ throughout the surveillance period. This control strategy has resulted in a reduction of $\dot{w}_{f}$ during the surveillance period which reaches approximately $2.5 \%$ relative to the nominal rotor configuration. The spikes in $\dot{w}_{f}$ observed during the surveillance period are due to the frequent banked turns carried out in order to "circle-around" the designated

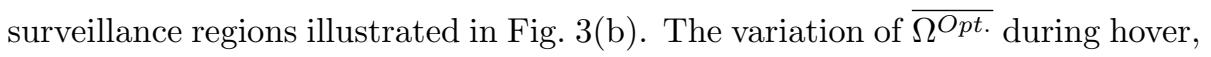
climb, and descent is similar to that described for the PATM operation.

A considerably more complex rotor speed schedule has been devised for SARM operation as shown in Fig. 11(c). It is shown that the rotorcraft undertakes a low-altitude $(h \approx 50 \mathrm{~m})$ Search And Rescue (SAR) activity at nearmaximum endurance flight speed $(V \approx 35 \mathrm{~m} / \mathrm{sec})$ for a duration of approximately $50 \%$ of total mission time. During this period the rotor control schedule has opted for substantially reduced rotor speed with $\overline{\Omega^{O p t} \text {. }} \approx 80 \%$. Furthermore, a reduced value of rotor speed has been applied for all encountered cruise segments with $\overline{\Omega^{O p t} .} \approx 83 \%$. This is attributed to the reduced cruise flight speed employed for the SARM operation which results in lower values of optimum $\Omega$.

A time-dependent reduction in $\dot{w}_{f}$ is observed in Figs. 11(b) and (c) during the surveillance and SAR segments of the LEM and SARM operations, respectively. This is due to the impact of gradual fuel burn during the mission duration resulting in reduced $W$ with increasing mission time. However, Figs. 11(b) and (c) also show that, for the investigated operations, this effect is not sufficient to alter the selected values of $\overline{\Omega^{O p t}}$ and $\theta_{t w}^{O p t}$. during these segments. Indicatively, it is noted that the fuel consumption during the surveillance and SAR parts only is estimated to be of the order of $112 \mathrm{~kg} / \mathrm{sec}$ and $62 \mathrm{~kg} / \mathrm{sec}$, respectively.

Hence, it has been demonstrated that the benefits offered by variable $\Omega$ and 
$\theta_{t w}$ in terms of operational performance and environmental impact are crucially dependent on the rotorcraft role. The reductions in fuel burn and $N O_{x}$ emissions are influenced by the proximity of the mission flight conditions to the "highpotential" zone of the operational envelope where the impact of variable $\Omega$ and $\theta_{t w}$ is considerable. It has been shown that, for TEL rotorcraft, the achieved deltas can vary up to an order of magnitude depending on mission specification.

\section{Conclusions}

This work investigated the potential improvements on operational performance and environmental impact of rotorcraft, stemming from the implementation of optimal variable rotor speed and active blade twist schedules at mission level. A comprehensive code was deployed comprising models for helicopter flight dynamics, rotor blade aeroelasticity, engine performance simulation, gaseous emission prediction, and flight path analysis. A holistic DSE and optimization strategy was devised including methods for DOE, RSM, and global optimization. The overall framework was deployed to devise optimally configured rotor trim schedules in terms of variable rotor speed and active blade twist across the operational envelope. The devised rotor control schedules were subsequently applied to evaluate the potential of the investigated technologies for a representative TEL rotorcraft operating within realistic mission scenarios.

It has been shown that the effectiveness of variable rotor speed and active blade twist on the operational performance and environmental impact of rotorcraft is significantly dependent on the type of operation. It has been demonstrated that the improvements in mission fuel burn and $\mathrm{CO}_{2}$ emissions can range between $-0.5 \%$ and $-5.0 \%$ depending on rotorcraft role. A larger improvement has been noted in terms of $N O_{x}$ gaseous emissions which can range between $-0.67 \%$ and $-7.91 \%$, depending on operational procedures. It has been argued that the obtained improvements are dependent on the proximity of the operating conditions to the "high-potential" zone of the operational envelope where the impact of variable rotor speed and blade twist becomes prominent. With respect to the influence of $\Omega$, it has been shown that these are established near 
the vicinity of the operational envelope where the rotor blade profile power requirement is maximized relative to the induced and parasitic counter-parts. As a result, the influence of optimal $\Omega$ is maximized for operating conditions associated with low gross weight $W$, low density altitude $h$, and near maximum endurance flight speed $V$. The analyses carried out suggest that the impact of $\Omega$ and $\theta_{t w}$ on fuel flow can range up to $-15 \%$ for strictly "light and low" operations at near-maximum endurance flight speed. With respect to TEL rotorcraft operated within LEM and SARM scenarios, it is expected that these concepts will offer performance improvements reaching up to $-5 \%$ and $-8 \%$ in terms of fuel burn and $N O_{x}$ emissions, respectively. The developed approach constitutes an enabling technology for the assessment of conceptual technologies at multiple levels of assessment including aircraft-engine, mission, and operational levels.

\section{References}

[1] Steiner, J. H., An Investigation of Performance Benefits and Trim Requirements of a Variable Speed Helicopter Rotor, Master's thesis, Pennsylvania State University, 2008.

[2] Miste, G. A., Benini, E., Garavello, A., and Gonzalez-Alcoy, M., "A Methodology for Determining the Optimal Rotational Speed of a Variable RPM Main Rotor/Turboshaft Engine System," Journal of the American Helicopter Society, Vol. 60, No. 3, 2015, pp. 111.

[3] Miste, G. A. and Benini, E., "Variable-Speed Rotor Helicopters: Performance Comparison Between Continuously Variable and Fixed-Ratio Transmissions," Journal of Aircraft, Vol. 53, (5), 2016.

[4] Padfield, G. D., Helicopter Flight Dynamics, Blackwell Publishing, Oxford, England, UK, 2007.

[5] Mistry, M. and Gandhi, F., "Helicopter Performance Improvement with Variable Rotor Radius and RPM," Journal of the American Helicopter Society, Vol. 59, (4), 2014, pp. $17-35$.

[6] Bowen-Davies, G. M. and Chopra, I., "Aeromechanics of a Slowed Rotor," Journal of the American Helicopter Society, Vol. 60, (3), 2015, pp. 1-13.

[7] Bir, G., Chopra, I., and Nguyen, K., "Development of UMARC (University of Maryland Advanced Rotorcraft Code)," 46th Annual National Forum of the American Helicopter Society, Washington, D. C., May 1990. 
[8] Han, D., Dong, C., and Barakos, G. N., "Performance Improvement of Variable Speed Rotors by Gurney Flaps," Aerospace Science and Technology, Vol. 81, (10), 10 2018, pp. $118-127$.

[9] Bowen-Davies, G. M. and Chopra, I., "Performance and Loads Predictions of a MachScaled Rotor at High Advance Ratios," Journal of the American Helicopter Society, Vol. 61, (3), 2016.

[10] Pagano, A., Ameduri, S., Cokonaj, V., Prachar, A., Zachariadis, Z., and Drikakis, D., "Helicopter Blade Morphing Strategies Aimed at Mitigating Environmental Impact," Journal of Theoretical and Applied Mechanics, Vol. 49, (4), 2011.

[11] Han, D., Yang, K., and Barakos, G. N., "Extendable Chord for Improved Helicopter Rotor Performance," Aerospace Science and Technology, Vol. 80, (9), 9 2018, pp. 445451.

[12] You, Y. and Jung, S. N., "Optimum Active Twist Input Scenario for Performance Improvement and Vibration Reduction of a Helicopter Rotor," Aerospace Science and Technology, Vol. 63, (4), 4 2017, pp. 18-32.

[13] Chen, P. C. and Chopra, I., "Wind Tunnel Test of a Smart Rotor Model with Individual Blade Twist Control," Journal of Intelligent Material Systems and Structures, Vol. 8, (5), 1997, pp. 414-425.

[14] Wilbur, M. L., Mirick, P. H., Yeager, W. T., Langston, C. W., Cesnik, C. E., and Shin, S., "Vibratory Loads Reduction Testing of the NASA/Army/MIT Active Twist Rotor," Journal of the American Helicopter Society, Vol. 47, (2), 2002, pp. 123-133.

[15] Zhang, Q., Hoffmann, F., and van der Wall, B. G., "Benefit Studies for Rotor with Active Twist Control using Weak Fluid-Structure Coupling," 35th European Rotorcraft Forum 2009 (ERF 2009), Hamburg, Germany, 92009.

[16] van der Wall, B. G., "An Analytic Model of Unsteady Profile Aerodynamics and its Application to a Rotor Simulation Program," 15th European Rotorcraft Forum, Amsterdam, Netherlands, 1989.

[17] RaddatzJens, J. and Fassbender, K., "Block Structured Navier-Stokes Solver FLOWer," Notes on Numerical Fluid Mechanics and Multidisciplinary Design (NNFM), Vol. 89, Springer, Berlin, Heidelberg, 2005.

[18] Han, D., Pastrikakis, V., and Barakos, G. N., "Helicopter Performance Improvement by Variable Rotor Speed and Variable Blade Twist," Aerospace Science and Technology, Vol. 54, 7 2016, pp. 164-173. 
[19] Bernhard, A. P. and Wong, J., "Wind-Tunnel Evaluation of a Sikorsky Active Rotor Controller Implemented on the NASA/ARMY/MIT Active Twist Rotor," Journal of the American Helicopter Society, Vol. 50, (1), 2005, pp. 65-81.

[20] Goulos, I., Pachidis, V., and Pilidis, P., "Helicopter Rotor Blade Flexibility Simulation for Aeroelasticity and Flight Dynamics Applications," Journal of the American Helicopter Society, Vol. 59, (4), October 2014.

[21] Goulos, I. and Pachidis, V., "Real-time aero-elasticity simulation of open rotors with slender blades for the multidisciplinary design of rotorcraft," Journal of Engineering for Gas Turbines and Power, Vol. 137, No. 1, 2015, pp. 012503.

[22] Li, Y. G., Marinai, L., Gatto, E. L., Pachidis, V., and Pilidis, P., "Multiple-Point Adaptive Performance Simulation Tuned to Aeroengine Test-Bed Data," Journal of Propulsion and Power, Vol. 25, (3), 2009, pp. 635-641.

[23] Goulos, I., Ali, F., Tzanidakis, K., Pachidis, V., and d'Ippolito, R., "A Multidisciplinary Approach for the Comprehensive Assessment of Integrated Rotorcraft-Powerplant Systems at Mission Level," Journal of Engineering for Gas Turbines and Power, Vol. 137, No. 1, 2015, pp. 012603.

[24] Ortiz-Carretero, J., Castillo-Pardo, A., Goulos, I., and Pachidis, V., "Impact of Adverse Environmental Conditions on Rotorcraft Operational Performance and Pollutant Emissions," Journal of Engineering for Gas Turbines and Power, Vol. 140, (2), 2017.

[25] Goulos, I., Giannakakis, P., Pachidis, V., and Pilidis, P., "Mission Performance Simulation of Integrated Helicopter-Engine Systems Using an Aeroelastic Rotor Model," ASME J. Eng. Gas Turbines and Power, Vol. 135, (9), 2013.

[26] Lorenzen, T. and Anderson, V., Design of Experiments: A No-Name Approach, CRC Press, 1993.

[27] Bayraktar, H. and Turalioglu, F., "A Kriging-based approach for locating a sampling site in the assessment of air quality," Stochastic Environmental Research and Risk Assessment, Vol. 19, 2005, pp. 301-305.

[28] Deb, K., Pratap, A., Agarwal, S., and Meyarivan, T., "A Fast and Elitist Multiobjective Genetic Algorithm: NSGA-II," IEEE Transactions on Evolutionary Computation, Vol. 6, (2), April 2002, pp. $182-197$.

[29] Ali, F., Tzanidakis, K., Goulos, I., Pachidis, V., and d'Ippolito, R., "Optimized Regenerative Powerplant Configurations Targeting Improved Rotorcraft Operational and Environmental Performance," Journal of the American Helicopter society, Vol. 60, No. 2, 2015, pp. 1-12. 
[30] Goulos, I., "Modelling the Aeroelastic Response and Flight dynamics of a Hingeless Rotor Helicopter Including the Effects of Rotor-Fuselage Aerodynamic Interaction," The Aeronautical Journal, Vol. 119, No. 1214, 2015, pp. 433-478.

[31] Goulos, I., Pachidis, V., and Pilidis, P., "Flexible Rotor Blade Dynamics for Helicopter Aeromechanics Including Comparisons with Experimental Data," The Aeronautical Journal, Vol. 119, (1213), March 2015, pp. 301-342.

[32] Goulos, I., Pachidis, V., and Pilidis, P., "Lagrangian Formulation for the Rapid Estimation of Helicopter Rotor Blade Vibration Characteristics," The Aeronautical Journal, Vol. 118, (1206), 8 2014, pp. 861-901.

[33] Castillo-Pardo, A., Goulos, I., and Pachidis, V., "Modelling and Analysis of Coupled Flap-Lag-Torsion Vibration Characteristics Helicopter Rotor Blades," Proceedings of the Institution of Mechanical Engineers, Part G: Journal of Aerospace Engineering, Vol. 231, No. 10, 2017, pp. 1804-1823.

[34] Eurocontrol, WGS 84 Implementation Manual., Eurocontrol, 1998.

[35] Macmillan, W. L., Development of a Module Type Computer Program for the Calculation of Gas Turbine Off Design Performance, Ph.D. thesis, Department of Power and Propulsion, Cranfield University, 1974.

[36] Peters, D. A., Boyd, D. D., and He, C. J., "Finite-State Induced-Flow Model for Rotors in Hover and Forward Flight," Journal of the American Helicopter Society, Vol. 34, (4), October 1989, pp. 5-17.

[37] Peters, D., "How dynamic inflow survives in the competitive world of Rotorcraft aerodynamics the Alexander Nikolsky honorary lecture," Journal of the American Helicopter Society, Vol. 54, No. 1, 2009, pp. 1-15.

[38] Leishman, J. G. and Beddoes, T. S., "A Semi-Empirical Model for Dynamic Stall," Journal of the American Helicopter Society, Vol. 34, (3), July 1989, pp. 3-17.

[39] Goulos, I., "An Improved Analytical Approach for Modeling the Effect of Rotor Wake Curvature Using Finite-State Induced Flow Models," Journal of the American Helicopter Society, Vol. 61, No. 3, 2016, pp. 1-16.

[40] Cheeseman, I. C. and Bennet, W. E., "The effect of the Ground on a Helicopter Rotor in Forward Flight," Aeronautical Research Council, R \& M No 3021, 1957.

[41] Pitt., D. M. and Peters, D. A., "Theoretical Prediction of Dynamic Inflow Derivatives," Vertica, Vol. 5, (1), March 1981, pp. 21-34. 
[42] Celis, C., Moss, J. B., and Pilidis, P., "Emissions Modelling for the Optimisation of Greener Aircraft Operations," Proceedings of ASME Turbo Expo 2009, Power for Land, Sea and Air, Orlando, Florida, USA, 8-12 June 2009.

[43] Olsson, A., Sandberg, G., and Dahlblom, O., "On Latin hypercube sampling for structural reliability analysis," Structural Safety, Vol. 25, No. 1, 2003, pp. 47 - 68.

[44] Kohavi, R., "A Study of Cross-Validation and Bootstrap for Accuracy Estimation and Model Selection," Proceedings of the Fourteenth International Joint Conference on Artificial Intelligence, Vol. 2, 1995, p. 11371143.

[45] Gunston, B., Jane's Aero-engines, Jane's Information Group, 1996.

[46] Peterson, R. L., Maier, T., Langer, H. J., and Trnapp, N., "Correlation of Wind Tunnel and Flight Test Results of a Full-Scale Hingeless Rotor," Proceedings of the American Helicopter Society Aeromechanics Specialist Conference, San Fransisco, California, January 1994.

[47] Staley, J. A., "Validation of Rotorcraft Flight Simulation Program through Correlation with Flight Data for Soft-in-plane Hingeless Rotor," ARMY AIR MOBILITY RESEARCH AND DEVELOPMENT LAB FORT EUSTIS VA EUSTIS DIRECTORATE, USAAMRDL-TR-75-50, 1976.

[48] Karamolegkos, K., Goulos, I., Pachidis, V., Stevens, J., Smith, C., Thevenot, L., and dIppolito, R., "Helicopter Mission Analysis Using a Multidisciplinary Simulation Framework," Proceedings of ASME Turbo Expo 2014: Turbine Technical Conference and Exposition, 2014.

[49] Fan, J. and Gijbels, I., Local Polynomial Modelling and Its Applications: Monographs on Statistics and Applied Probability 66, CRC Press, Boca Raton, FL 33487, USA, March 1996.

[50] Bramwell, A. R. S., Done, G., and Balmford, D., Bramwell's Helicopter Dynamics, Butterworth-Heinemann, Oxford, England, UK, 2001.

[51] Hotelling, H., "New Light in the Correlation Coefficient and its Transforms," Journal of the Royal Statistical Society, Vol. 15, (2), No. 193-232, 1953.

[52] Walsh, P. and Fletcher, P., Gas Turbine Performance Engineering, Blackwell Publishing, 2004. 
2019-03-28

\section{Variable rotor speed and active blade twist for civil rotorcraft: optimum scheduling, mission analysis, and environmental impact}

Goulos, loannis

Elsevier

Goulos I and Bonesso M., Variable rotor speed and active blade twist for civil rotorcraft: optimum scheduling, mission analysis, and environmental impact, Aerospace Science and Technology, Volume 88, May 2019, pp. 444-456

https://doi.org/10.1016/j.ast.2019.03.040

Downloaded from Cranfield Library Services E-Repository 